\title{
Holistic processing of facial identity in developmental prosopagnosia
}

\section{Article}

\section{Accepted Version}

Creative Commons: Attribution-Noncommercial-No Derivative Works 4.0

Tsantani, M., Gray, K. L. H. and Cook, R. (2020) Holistic processing of facial identity in developmental prosopagnosia. Cortex, 130. pp. 318-326. ISSN 0010-9452 doi: https://doi.org/10.1016/j.cortex.2020.06.003 Available at https://centaur.reading.ac.uk/91180/

It is advisable to refer to the publisher's version if you intend to cite from the work. See Guidance on citing.

To link to this article DOI: http://dx.doi.org/10.1016/j.cortex.2020.06.003

Publisher: Elsevier

All outputs in CentAUR are protected by Intellectual Property Rights law, including copyright law. Copyright and IPR is retained by the creators or other copyright holders. Terms and conditions for use of this material are defined in the End User Agreement.

\section{www.reading.ac.uk/centaur}

\section{CentAUR}

Central Archive at the University of Reading

Reading's research outputs online 
In press at: Cortex

Running head: Holistic face processing in developmental prosopagnosia

\title{
Holistic processing of facial identity in developmental prosopagnosia
}

\author{
Maria Tsantani ${ }^{1}$, Katie L. H. Gray ${ }^{2}$, Richard Cook $^{1,3^{*}}$ \\ ${ }^{1}$ Department of Psychological Sciences, \\ Birkbeck, University of London, London, U.K. \\ ${ }^{2}$ School of Psychology and Clinical Language Sciences, \\ University of Reading, Reading, U.K. \\ ${ }^{3}$ Department of Psychology, \\ University of York, York, U.K.
}

${ }^{*}$ Corresponding author:

richard.cook@bbk.ac.uk

Department of Psychological Sciences,

Birkbeck, University of London,

London, U.K. 


\section{Abstract}

The nature of the perceptual deficit seen in developmental prosopagnosia remains poorly understood. One possibility is that these individuals experience face recognition difficulties because they fail to process faces holistically; they may be less able to analyze distal regions in parallel and therefore struggle to integrate information from different regions into a unified perceptual whole. Consequently, developmental prosopagnosics may be forced to base perceptual decisions on a slow, effortful piecemeal analysis of local facial features. In the present study, we sought to test this view by comparing the face recognition of developmental prosopagnosics and typical observers under two viewing conditions: when target faces were briefly presented in their entirety, and when they were inspected region-byregion through a dynamic aperture. If developmental prosopagnosics are forced to base perceptual decisions on information accumulated from a serial piecemeal analysis, one would expect little if any decrement in performance when target faces are viewed through apertures. Contrary to this prediction, however, developmental prosopagnosics showed strong aperture effects comparable with typical observers; their perceptual decisions were more accurate in the whole-face condition than when targets were viewed through the aperture. As expected, the developmental prosopagnosics were less accurate than typical controls when judging briefly presented faces shown in their entirety. Strikingly, however, they were also less able to accumulate perceptual evidence from a serial region-by-region analysis, than typical observers. Our results suggest that the perceptual problems seen in this population arise from imprecise descriptions of local regions, not aberrant holistic processing.

\section{Key words:}

Developmental prosopagnosia; holistic face processing; facial identity; famous face recognition; aperture viewing. 


\section{Introduction}

Developmental prosopagnosia $^{1}(\mathrm{DP})$ is a neurodevelopmental condition characterized by lifelong face recognition difficulties, that occur despite normal intelligence, typical low-level vision, and no history of brain damage (Behrmann \& Avidan, 2005; Cook \& Biotti, 2016; Duchaine \& Nakayama, 2006b; Susilo \& Duchaine, 2013). DP impairs the perception of same and other-ethnicity faces alike (Cenac, Biotti, Gray, \& Cook, 2019). Many DPs experience subtle problems recognising facial expressions (Biotti \& Cook, 2016) and facial sex (Esins, Schultz, Stemper, Kennerknecht, \& Bulthoff, 2016; Marsh, Biotti, Cook, \& Gray, 2019), and some show signs of co-occurring body (Biotti, Gray, \& Cook, 2017) and object recognition difficulties (Geskin \& Behrmann, 2017; Gray, Biotti, \& Cook, 2019). Cases of DP were once thought to be rare (McConachie, 1976), however current estimates suggest that $\sim 2 \%$ of the general population may experience lifelong face recognition difficulties severe enough to disrupt their daily lives (Kennerknecht et al., 2006; Kennerknecht, Ho, \& Wong, 2008).

When viewed by typical observers, faces are thought to engage holistic processing whereby distal features are processed in parallel and integrated into a unified perceptual whole, for the purposes of accurate and efficient interpretation (Farah, Wilson, Drain, \& Tanaka, 1998; Maurer, Le Grand, \& Mondloch, 2002; McKone \& Yovel, 2009; Piepers \& Robbins, 2013; Richler, Wong, \& Gauthier, 2011). Evidence for this view is provided by the composite face illusion (Gray et al., 2020; Hole, 1994; Young, Hellawell, \& Hay, 1987). When the bottom half of one face is spatially aligned with the top half of another, the two halves appear to fuse together perceptually, altering observers' perception of the individual regions. Consistent with theories of holistic face processing, the composite face illusion appears to reveal a tendency to integrate information from distal facial regions (Murphy, Gray, \& Cook, 2017; Rossion, 2013).

Theories of holistic face processing have been criticised because of their informal formulation (Burton, Schweinberger, Jenkins, \& Kaufmann, 2015; Fitousi, 2015, 2016; Wenger \& Townsend, 2001). In their strongest form, however, these accounts posit that holistic processing is gated, and only recruited in the presence of an intact faciotopy; i.e., the detection of two eyes above a nose, above a mouth (Farah et al., 1998; McKone, Kanwisher, \& Duchaine, 2007; McKone \& Yovel, 2009; Tsao \& Livingstone, 2008). For this reason, faces that are inverted (McKone \& Yovel, 2009; Rossion, 2008), have their top and bottom halves misaligned (Murphy et al., 2017; Rossion, 2013), or are scrambled so that features appear at 
noncanonical locations (Tanaka \& Farah, 1993), are not thought to engage holistic processing.

Relative to typical observers, it has been suggested that individuals with DP experience face recognition problems because they are less able to process faces holistically (Avidan, Tanzer, \& Behrmann, 2011; DeGutis, Cohan, \& Nakayama, 2014; Palermo et al., 2011; Towler, Fisher, \& Eimer, 2018). In light of this possibility, there has been considerable interest in whether DPs show reduced susceptibility to the composite face illusion, thought to index holistic face processing. To date, however, studies of the composite face illusion in DP have yielded mixed results. While some studies have reported diminished susceptibility to the illusion in DP (Avidan et al., 2011; Liu \& Behrmann, 2014; Palermo et al., 2011), others have found typical susceptibility in this population (Biotti, Wu, et al., 2017; Le Grand et al., 2006; Susilo et al., 2010; Ulrich et al., 2017). Given the mixed evidence yielded by composite face paradigms, it is important that we find new ways to test holistic face processing in DP.

Aperture paradigms - whereby observers judge stimuli inspected through a dynamic viewing window - represent a promising new approach (Murphy \& Cook, 2017; Murphy, Gray, \& Cook, 2020; Van Belle, De Graef, Verfaillie, Rossion, \& Lefèvre, 2010). By forcing observers to inspect faces through a viewing window, aperture paradigms impede holistic face processing. While participants still have the opportunity to inspect each local feature, they are unable to process distal regions in parallel. Instead, observers must process faces in a serial region-by-region manner, similar to the piecemeal analysis thought to be engaged when viewing non-face objects (Biederman, 1987; McKone et al., 2007). The results from aperture paradigms are important because they allow vision scientists to assess directly the causal contribution of holistic processing to perceptual judgements about faces researchers can block holistic processing and examine the consequences.

In the present study, we employed a fixed-trajectory aperture paradigm (Murphy \& Cook, 2017; Murphy et al., 2020) to test the aberrant holistic processing account of DP (Avidan et al., 2011; DeGutis et al., 2014; Palermo et al., 2011; Towler et al., 2018). We compared the ability of DPs $(N=22)$ and typical observers $(N=25)$ to identify famous faces under two viewing conditions: when faces were briefly presented in their entirety, or revealed region-byregion by a dynamic aperture. If the aberrant holistic processing account is correct, aperture viewing should impair the face recognition of typical observers, who are thought to process 
upright faces holistically, but have little or no effect on the face recognition of the DPs, who are thought to employ a piecemeal analysis of local features.

\section{Research transparency and openness}

Neither the study procedure nor the intended analyses were pre-registered prior to the start of the research. In the following sections we report how we determined our sample size, all data exclusions, all inclusion criteria, and whether inclusion/exclusion criteria were established prior to data analysis. All manipulations and all measures in the study are reported. Study materials, including the experimental program and example stimuli, and anonymised data files and analysis scripts are available through the Open Science Framework (https://osf.io/qw9z6/?view only=a5ac306efe274c39a6fab50fecef3750). Summary data for the experimental tasks are provided as supplementary online material. Ethical approval was granted by the local ethics committee. The research was conducted in line with the ethical guidelines provided by the 6th (2008) Declaration of Helsinki.

\section{Participants}

Twenty-two individuals with DP ( 4 males, $M_{\text {age }}=36.91$ years, $S D_{\text {age }}=11.88$ years) and 25 typical controls (14 males, $M_{\text {age }}=34.56$ years, $S D_{\text {age }}=8.38$ years) took part in the study. The mean age of the groups did not differ significantly $\left[t(45)=.791, p=.433, d=.227, \mathrm{Cl}_{95 \%}\right.$ $=-.345, .805]$. Sample size was determined a-priori based on similar group studies of DP (Biotti, Gray, et al., 2017; Cenac et al., 2019; Shah, Gaule, Gaigg, Bird, \& Cook, 2015). For the purposes of the experiment it was essential that participants knew the nationality of the famous people presented. At the end of the experiment participants therefore completed a name categorization task, in which they were asked to identify the nationality of each celebrity when given their name (see Section 6). Two of the DPs and five of the typical controls were replacements for individuals who failed to score at least $80 \%$ correct on this name categorization task.

DP participants were recruited through www.troublewithfaces.org and reported lifelong face recognition difficulties in the absence of brain injury and psychiatric disorder. Diagnostic decisions were based primarily on participants' scores on the Cambridge Face Memory Test (CFMT; Duchaine \& Nakayama, 2006a) and the Twenty-Item Prosopagnosia Index (PI20; Gray, Bird, \& Cook, 2017; Shah, Gaule, Sowden, Bird, \& Cook, 2015). DPs also completed the Cambridge Face Perception Test (CFPT; Duchaine, Germine, \& Nakayama, 2007) to index the severity of their perceptual encoding difficulties, and the Cambridge Car Memory Test (CCMT; Dennett et al., 2011), to assess their within-class object recognition ability. The 
use of convergent self-report evidence and scores on objective, computer-based tasks may be a particularly effective approach to the identification and classification of DP; for example, less than $1.5 \%$ of the general population score below $65 \%$ on the CFMT and more than 65 on the PI20 (Gray et al., 2017). Diagnostic information for each DP is provided in Table 1.

Table-1

In order to participate in the study, individuals were required to be aged 18 to 65 years-old, to have normal or corrected-to-normal visual acuity, and to have had no clinical diagnosis of autism spectrum disorder or schizophrenia. These inclusion criteria were identified at the outset. We recruited control participants who had been resident in the UK for a minimum of 10 years, to ensure that they would be familiar with the famous people whose names and faces were presented in the experiment. None of the typical controls scored above 60 on the PI20 $(M=39.3, S D=10.5$, range $=28: 59)$, and scores were significantly lower compared with the DP group $(M=80.1, S D=6.8$, range $=70: 95)[t(45)=15.662, p<.001, d=4.501$, $\left.\mathrm{Cl}_{95 \%}=3.468,5.674\right]$. All participants were tested in person under controlled lab conditions. All participants provided informed consent and were fully debriefed after the experimental procedure.

\section{Categorizing celebrity faces by nationality}

\subsection{Stimuli and Procedure}

We obtained 48 images of famous people (24 British and 24 American) through internet searches. There were 12 men and 12 women of each nationality. Famous people included actors, musicians, politicians, and TV personalities (a complete list is provided in Supplementary materials Table S1). We tried to ensure that the British and US individuals were drawn from similar professions, and did not differ systematically in terms of age and attractiveness. All faces were front-facing with a neutral or smiling facial expression. External features were occluded using an oval window. The facial images were converted to greyscale and equated for luminance and contrast using the SHINE toolbox (Willenbockel et al., 2010) in Matlab (The MathWorks, Natick, MA).

The to-be-judged images were presented to participants in a video sequence. Two video sequences (one 'whole-face', one 'aperture') were created for each of the 48 faces, resulting in 96 videos in total. Sequences were constructed from a series of bitmap images, compiled in Matlab and saved as uncompressed avi files. Whole-face sequences presented a single static face in its entirety for $500 \mathrm{~ms}$ (Figure 1a). Faces were presented briefly in this condition 
to prevent observers employing a protracted serial analysis of the local features. Aperture sequences depicted a viewing window moving over the facial image with a vertical directionality, starting at the top and moving downwards (Figure 1b). All sequences started and ended with a black display. The aperture height was $12 \%$ of the overall height of the face $\left(6^{\circ}\right.$ of visual arc when viewed at $58 \mathrm{~cm}$ ) and took 6.2 secs to move across the face. The timing of the sequence and frame rate (30 frames per second) yielded slow and smooth aperture motion. A slow and smooth aperture transition helps ensure that participants have ample time to inspect local features, and keeps the fixation / attentional demands minimal.

Figure-1

Trials presented a single video sequence on an LCD display ( $60 \mathrm{~Hz}$ refresh rate). Following the offset of each sequence, observers were asked to make a binary categorization judgement about the nationality of the famous individual depicted; i.e., "British or American?". Participants registered their decision with a keypress response. Each of the 96 face videos (48 whole face, 48 aperture) was presented twice, resulting in 192 trials in total. The trials were divided into two mini-blocks, each of which presented all stimuli once in a random order. The experiment was programmed in Matlab using the Psychophysics Toolbox (version 3; Brainard, 1997; Pelli, 1997) and was completed under controlled lab conditions at Birkbeck, University of London.

Participants' nationality categorization responses were analyzed using signal detection theory (Macmillan \& Creelman, 1991). A response of 'British' was classed as a 'hit' if it followed the presentation of a British person's face and as a 'false alarm' if it followed the presentation of an American person's face. The resulting d-prime ( $d$ ) statistics were used to infer participants' ability to recognize, and thereby classify the nationality of the famous faces in the whole-face and aperture presentation conditions. Here we report unadjusted estimates of $d^{\prime}$ based on all trials. However, we also derived a second set of adjusted $d^{\prime}$ estimates having discounted those trials that presented a celebrity that was not known to the participant by name. Analysis of these adjusted values produced virtually identical results (see Supplementary materials). Cohen's $d$ effect sizes and their confidence intervals were computed using ESCI (Cumming, 2016).

\subsection{Results}

The distributions of $d^{\prime}$ 'statistics (Figure 2) were subjected to ANOVA with Viewing Condition (whole-face, aperture) as a within-subjects factor, and Group (DP, control) as a betweensubjects factor. The analysis revealed a significant main effect of Viewing Condition $[F(1,45)$ 
$\left.=46.319, p<.001, \eta^{2}=.507\right]$, whereby whole-face presentation afforded superior categorization. Both the control (whole-face: $M=2.685, S D=.903$; aperture: $M=2.248, S D$ $=.886)\left[t(24)=3.903, p<.001, d=.474, \mathrm{Cl}_{95 \%}=.204, .767\right]$ and DP (whole-face: $M=1.741$, $S D=.618$; aperture: $M=1.210, S D=.686)\left[t(21)=6.450, p<.001, d=.785, \mathrm{Cl}_{95 \%}=.461\right.$, 1.157] groups showed significant effects of Viewing Condition. The analysis also revealed a significant main effect of Group $\left[F(1,45)=20.293, p<.001 \eta^{2}=.311\right]$, whereby the typical observers out-performed the DPs. Relative to the typical controls, the DPs were impaired in both the whole-face $\left[t(45)=4.125, p<.001, d=1.186, \mathrm{Cl}_{95 \%}=0.576,1.825\right]$ and aperture $\left[t(45)=4.443, p<.001, d=1.277, \mathrm{Cl}_{95 \%}=0.661,1.952\right]$ viewing conditions. We observed no interaction between Viewing Condition and Group $\left[F(1,45)=.435, p=.513, \eta^{2}=.010\right]$.

Figure-2

The DP group contained a smaller proportion of male observers than the group of typical controls $\left[X^{2}(1)=7.083, p=.008\right]$. Unlike observer age (Germine, Duchaine, \& Nakayama, 2011), observer gender is thought to have relatively little influence on face identification ability (Bowles et al., 2009; Duchaine \& Nakayama, 2006a). Nevertheless, we re-ran the foregoing analyses with observer gender as an additional between-subjects factor to determine whether the imbalance had any effect on our results. As expected, none of the main effects or interactions approached significance (all $F s<.60$, all $p$ 's $>.45$ ).

It is possible that the performance of DPs and controls differed systematically across the two blocks; for example, DPs may have derived less benefit from perceptual learning. To test this possibility, we computed separate estimates of $d^{\prime}$ for block-1 (B1) and block-2 (B2), and conducted a further ANOVA with Viewing Condition (whole-face, aperture) and Block (B1, B2) as within-subjects factors, and Group (DP, control) as a between-subjects factor. As expected, we found main effects of Viewing Condition $\left[F(1,45)=51.743, p<.001, \eta^{2}=.535\right]$ and Group $\left[F(1,45)=21.246, p<.001, \eta^{2}=.321\right]$, and no Viewing Condition $\times$ Group interaction $\left[F(1,45)=.984, p=.326, \eta^{2}=.021\right]$. However, the analysis also revealed a main effect of Block $\left[F(1,45)=23.958, p<.001, \eta^{2}=.347\right]$. Superior categorization performance was seen in B2 compared with B1 both for the DPs (B1 whole-face: $M=1.666, S D=.553$; B2 whole-face: $M=1.843, S D=.805$; $B 1$ aperture: $M=.986, S D=.738$; B2 aperture: $M=$ $1.459, S D=.734$ ) and controls (B1 whole-face: $M=2.575, S D=.857$; B2 whole-face: $M=$ 2.715, $S D=.804$; B1 aperture: $M=2.041, S D=.853$; B2 aperture: $M=2.443, S D=.928$ ). We also observed a significant interaction between Block and Viewing Condition $[F(1,45)=$ 5.937, $\left.p=.019, \eta^{2}=.117\right]$, whereby a greater improvement was seen in the aperture 
condition, than in the whole-face condition. Seeing the famous faces in their entirety in B1 likely helped observers in both groups recognize those individuals in the aperture condition of B2. Crucially, however, there was no Block $\times$ Group interaction $[F(1,45)=.196, p=.660$, $\left.\eta^{2}=.004\right]$, nor did we observe a Block $\times$ Viewing Condition $\times$ Group interaction $[F(1,45)=$ $.019, p=.891, \eta^{2}=.000$ ], indicating that the DPs and controls showed similar levels of improvement across the two blocks.

Finally, we examined whether any of the diagnostic measures (PI20, CFMT, CFPT, CCMT) correlated with measures of task performance (whole-face $d^{\prime}$, aperture $d^{\prime}$, aperture decrement) within the sample of DPs. None of the correlations observed reached significance (Table 2).

Table-2

\section{Famous face recognition under free viewing conditions}

In the main experiment, participants judged faces that had their external features occluded, either when viewed in their entirety for $500 \mathrm{~ms}$ or inspected through a dynamic aperture that revealed the target face region-by-region. Neither of these viewing conditions closely resemble the conditions in which we typically encounter familiar faces. Moreover, participants in the main experiment were asked to identify the nationality of the celebrity, not report the individuals' identity per se. We therefore sought to confirm that performance in our contrived viewing conditions related to face recognition ability under naturalistic free-viewing conditions. Participants viewed each of the 48 faces used in the main experiment, one at a time. This time the external features were left visible. Participants were asked to identify the individual shown by providing their name or other identifying information. They were free to inspect each face for as long as they wished and could respond in their own time. While participants knew that the faces were British or American celebrities, they had received no other feedback at this point.

\section{Figure-3}

The performance of the two groups is shown in Figure 3. As expected, the DPs $(M=68.7 \%$, $S D=16.0 \%)$ were able to identify fewer celebrities than the typical controls $(M=88.4 \%, S D$ $=10.6 \%)\left[t(45)=5.046, p<.001, d=1.450, \mathrm{Cl}_{95 \%}=.820,2.117\right]$. Significant correlation was seen between the estimates of categorization sensitivity derived in both the aperture and whole-face viewing conditions, and participants' identification ability under free-viewing 
conditions: this relationship was seen when the two groups were combined into a single sample [aperture: $r=.642, p<.001$; whole-face: $r=.727, p<.001$ ], and in the DP [aperture: $r=.423, p<.05$; whole-face: $r=.599, p<.01$ ] and control [aperture: $r=.563, p<.01$; wholeface: $r=.704, p<.001]$ groups independently. There was no effect of observer gender on the number of faces recognized $\left[t(45)=1.490, p=.143, d=.440, \mathrm{Cl}_{95 \%}=-.151,1.040\right]$. Importantly, these results indicate that our viewing conditions measure perceptual abilities that are meaningful outside the lab.

\section{Identifying the nationality of named celebrities}

In the final part of the study, all participants completed a name categorization task. Participants were presented with the names of the same 48 famous individuals in a random order. Upon viewing each name, participants were asked to indicate whether they knew the person, and whether the person was British or American. In each case, participants registered their response with a key press.

There was no significant difference in the number of names known by the DPs $(M=91.6 \%$, $S D=10.7 \%)$ and the typical controls $(M=96.2 \%, S D=6.2 \%)[t(45)=1.828, p=.074, d=$ $\left..525, \mathrm{Cl}_{95 \%}=-.052,1.115\right]^{2}$. When presented with the names of the 48 famous individuals used in the experiment, the DP group $(M=92.6 \%, S D=4.8 \%)$ and the typical controls $(M=$ $92.8 \%, S D=5.4 \%$ ) were closely matched in their ability (\% correct) to correctly categorize nationality $\left[t(45)=.146, p=.885, d=.042, \mathrm{Cl}_{95 \%}=-.531, .615\right]$. There was no effect of observer gender on the number of names recognized $\left[t(45)=.471, p=.640, d=.139, \mathrm{Cl}_{95 \%}\right.$ $=-.448, .729]$ or categorized $\left[t(45)=.755, p=.454, d=.223, \mathrm{Cl}_{95 \%}=-.365, .815\right]$.

Despite clear deficits identifying the famous individuals from their face, the DPs showed little or no impairment when categorising the individuals' nationality when given their name. The fact that the DPs knew the nationality of the famous individuals indicates that their performance in the main experiment was not constrained by a broader memory deficit, a problem retrieving semantic information, or poor knowledge of popular culture (e.g., Shah, Gaule, Sowden, et al., 2015).

\section{General discussion}

In the present study we used an aperture paradigm to test the hypothesis that individuals with DP have difficulties recognising faces because they struggle to process faces holistically (Avidan et al., 2011; DeGutis et al., 2014; Palermo et al., 2011; Towler et al., 2018). We asked participants with DP and typical controls to identify the nationality of 
famous individuals when their faces were briefly presented in their entirety, or inspected through a dynamic aperture. If DPs were forced to base perceptual decisions on information accumulated from a serial region-by-region inspection of faces, one would expect little if any decrement in performance when they are forced to view target faces through apertures. Contrary to this prediction, however, the categorisation ability of DPs and controls was disrupted to a similar degree by the aperture manipulation. The clear aperture effects shown by both groups suggest that typical observers and those with DP process faces holistically.

There has been considerable interest in whether DPs show reduced susceptibility to the composite face illusion, thought to index holistic face processing. To date, however, studies have yielded mixed results: some authors have reported diminished susceptibility in DP (Avidan et al., 2011; Liu \& Behrmann, 2014; Palermo et al., 2011), while others have found typical levels of susceptibility (Biotti, Wu, et al., 2017; Le Grand et al., 2006; Susilo et al., 2010; Ulrich et al., 2017). More broadly, there is increasing uncertainty about the functional significance of the composite face illusion (Murphy et al., 2017; Richler et al., 2011). Studies have found no association between illusion susceptibility and face identification ability in the typical population (e.g., Konar, Bennett, \& Sekuler, 2010) Similarly, there has been considerable debate about the perceptual, attentional, and decisional influences on the effect (Fitousi, 2015, 2016; Richler \& Gauthier, 2014). In light of these ongoing concerns, the results described here, obtained from a complementary test of holistic face processing, are important and timely.

Over the last twenty years, several different variants of holistic processing theory have been proposed. Some accounts argue that holistic processing helps observers represent the spatial relationships between local features (Maurer et al., 2002; Piepers \& Robbins, 2013), while others posit that feature descriptions and their spatial configuration are represented in a non-decomposable holistic representation (Farah et al., 1998). Similarly, some authors argue that the integrative processes that underlie the holistic processing of faces are domain-general; i.e., qualitatively similar to those recruited by non-face objects (Richler \& Gauthier, 2014; Richler et al., 2011), while others have advanced face-specific accounts (McKone et al., 2007; Rossion, 2008, 2013).

Interestingly, a recent study found that susceptibility to the composite face illusion is unrelated to performance on other putative measures of holistic face processing, including the part-whole and face-inversion effects (Rezlescu, Susilo, Wilmer, \& Caramazza, 2017). In light of this finding and the range of different views expressed above, it is possible that 
"holistic face processing" is actually a collection of processes, not a unitary construct (also see: Maurer et al., 2002; Richler et al., 2011). Accordingly, we cannot exclude the related possibility that some form of holistic face processing is impaired in DP, but not revealed by our fixed-trajectory aperture paradigm. We note however, that many DPs - perhaps the majority - also show typical susceptibility to the composite face illusion (Biotti, Wu, et al., 2017; Le Grand et al., 2006; Susilo et al., 2010). The view that DPs process face holistically is therefore supported by convergent lines of evidence from very different paradigms.

Although our results are hard to reconcile with the aberrant holistic processing account of DP, they lend support to an alternative possibility. Tellingly, the DPs were not only less accurate than typical controls when judging faces briefly shown in their entirety, but they showed a similar level of impairment in the aperture condition. In other words, the DPs were less able to accumulate perceptual evidence from a serial region-by-region analysis than typical observers, and the extent of this difficulty corresponded closely to the level of impairment seen when judging faces shown in their entirety. These findings suggest that the perceptual problems seen in DP arise from imprecise descriptions of local regions, not from aberrant holistic processing. By way of analogy, impoverished representations of words may result from imprecise encoding of letters, not aberrant letter integration processes, per se. Consistent with this suggestion, DPs sometimes perform poorly in the misaligned conditions of face matching tasks designed to measure susceptibility to the composite face illusion (Liu \& Behrmann, 2014). Similarly, variability in local feature matching ability appears to contribute substantially to individual differences in face recognition seen in the typical population (DeGutis, Wilmer, Mercado, \& Cohan, 2013).

In the present study we employed a fixed-trajectory aperture manipulation in which a viewing window moves across the target image in a predetermined direction, at a predetermined rate (Murphy \& Cook, 2017; Murphy et al., 2020). Because it obscures the basic 'faciotopy' and prevents observers processing distal facial regions in parallel, leading theoretical accounts predict that this manipulation ought to block or impair holistic face processing (Murphy et al., 2017). The fact that observers show superior recognition performance for faces briefly presented in their entirety, than when given longer to inspect serially each local region in detail, accords with the view that some form of whole-face processing makes a necessary causal contribution to face perception (see also Murphy \& Cook, 2017; Murphy et al., 2020). However, we make no claim about the domain-specificity or -generality of the integrative processes impaired by the manipulation; for example, it remains unknown how fixed- 
trajectory aperture viewing affects the identification and discrimination of non-face objects of expertise.

A related 'gaze-contingent' paradigm has been used previously to study holistic face processing in typical observers (Van Belle, De Graef, Verfaillie, Rossion, et al., 2010) and prosopagnosic individuals (Van Belle, De Graef, Verfaillie, Busigny, \& Rossion, 2010; Verfaillie, Huysegems, De Graef, \& Van Belle, 2014). In this paradigm, the region of the target face revealed by the viewing window is determined by the gaze fixation of the participant. Consequently, the participant controls which parts of the stimulus are visible, how long they are visible, and in which order the regions are revealed. A particular advantage of the fixed-trajectory approach is that control over the stimulus resides with the experimenter. In the present study, we were thus able to ensure that all observers were exposed to the same visual information, for the same length of time, in the same order. Some readers might reason that the gaze-contingent approach allows participants to sample facial information 'naturally'. However, the paradigm appears to induce an unusual tendency to fixate on the top of the nose (e.g., Van Belle, De Graef, Verfaillie, Rossion, et al., 2010), possibly because a window centred on this point affords the best view of the eye region.

It has been suggested that individual differences in face recognition ability may sometimes reflect different patterns of gaze fixations employed by observers. For example, some DPs appear to spend less time examining internal facial features, in particular the eyes (Bobak, Parris, Gregory, Bennetts, \& Bate, 2017; Peterson et al., 2019). Conversely, so-called 'super-recognizers' - people with exceptional face recognition ability (Russell, Duchaine, \& Nakayama, 2009) - spend more time inspecting the nose region than typical observers (Bobak et al., 2017). In the context of this literature, the performance of DPs and typical observers on fixed-trajectory aperture tasks is particularly informative. Under these conditions, the aperture serves to "guide" observers' attention across the target image. As a result, it is possible to compare the performance of different observers in the knowledge that they have sampled the same regions of the face for the same length of time (cf. Verfaillie et al., 2014). The fact that we see a clear group difference in the aperture condition argues against the view that DPs are simply sampling information from the 'wrong' regions; rather, it appears that these individuals are less able to extract information from the regions they sample.

It has been noted previously that DPs find famous face recognition particularly challenging compared with tasks that involve the matching (e.g., CFMT) or sorting (e.g., CFPT) of 
unfamiliar faces (Bate et al., 2019). Current estimates suggest that typical observers frequently know more than 5000 faces (Jenkins, Dowsett, \& Burton, 2018). Matching a given facial percept to one of these stored representations therefore poses a considerable 'needlein-a-haystack' challenge, akin to a match-to-sample task with 5000 or more potential responses. While an imprecise perceptual description may sometimes suffice when matching and sorting unfamiliar faces, the ability to recognise familiar faces may require an extremely accurate perceptual representation. It is no surprise that individuals who form impoverished perceptual descriptions of faces (e.g., Biotti, Gray, \& Cook, 2019), find famous face recognition extremely difficult. 


\section{Footnotes}

${ }^{1}$ We use the term developmental prosopagnosia instead of congenital prosopagnosia to acknowledge the possibility that in some cases the disorder may appear during development and not necessarily from birth.

${ }^{2}$ The non-significant trend here is unsurprising. It is likely that prosopagnosics and typical controls sometimes apply different criteria when asked whether they "know" a particular celebrity. For example, the ability to bring a famous face to mind - something prosopagnosics find difficult - may influence responses to this question. Similarly, prosopagnosic participants may be less likely to say they "know" a celebrity if they have previously failed to recognise them, or are unsure of their ability to recognise them in the future. 


\section{Acknowledgements}

$\mathrm{RC}$ is supported by a Starting Grant awarded by the European Research Council (ERC2016-StG-715824). 


\section{References}

Avidan, G., Tanzer, M., \& Behrmann, M. (2011). Impaired holistic processing in congenital prosopagnosia. Neuropsychologia, 49(9), 2541-2552.

Bate, S., Bennetts, R. J., Gregory, N., Tree, J. J., Murray, E., Adams, A., . . Banissy, M. J. (2019). Objective patterns of face recognition deficits in 165 adults with self-reported developmental prosopagnosia. Brain Sciences, 9(6), 133.

Behrmann, M., \& Avidan, G. (2005). Congenital prosopagnosia: face-blind from birth. Trends in Cognitive Sciences, 9(4), 180-187.

Biederman, I. (1987). Recognition-by-components: a theory of human image understanding. Psychological Review, 94(2), 115-147.

Biotti, F., \& Cook, R. (2016). Impaired perception of facial emotion in developmental prosopagnosia. Cortex, 81, 126-136.

Biotti, F., Gray, K. L. H., \& Cook, R. (2017). Impaired body perception in developmental prosopagnosia. Cortex, 93, 41-49.

Biotti, F., Gray, K. L. H., \& Cook, R. (2019). Is developmental prosopagnosia best characterised as an apperceptive or mnemonic condition? Neuropsychologia, 124, 285-298.

Biotti, F., Wu, E., Yang, H., Jiahui, G., Duchaine, B., \& Cook, R. (2017). Normal composite face effects in developmental prosopagnosia. Cortex, 95, 63-76.

Bobak, A. K., Parris, B. A., Gregory, N. J., Bennetts, R. J., \& Bate, S. (2017). Eye-movement strategies in developmental prosopagnosia and "super" face recognition. Quarterly Journal of Experimental Psychology, 70, 201-217.

Bowles, D. C., McKone, E., Dawel, A., Duchaine, B., Palermo, R., Schmalzl, L., . . Y Yovel, G. (2009). Diagnosing prosopagnosia: effects of ageing, sex, and participant-stimulus ethnic match on the Cambridge Face Memory Test and Cambridge Face Perception Test. Cognitive Neuropsychology, 26(5), 423-455.

Brainard, D. H. (1997). The Psychophysics Toolbox. Spatial Vision, 10(4), 433-436. 
Burton, A. M., Schweinberger, S. R., Jenkins, R., \& Kaufmann, J. M. (2015). Arguments against a configural processing account of familiar face recognition. Perspectives on Psychological Science, 10(4), 482-496.

Cenac, Z., Biotti, F., Gray, K. L. H., \& Cook, R. (2019). Does developmental prosopagnosia impair identification of other-ethnicity faces? Cortex, 119, 12-19.

Cook, R., \& Biotti, F. (2016). Developmental prosopagnosia. Current Biology, 26(8), R312R313.

Cumming, G. (2016). ESCI: Exploratory software for confidence intervals [Computer software]. https://thenewstatistics.com/itns/esci/.

DeGutis, J., Cohan, S., \& Nakayama, K. (2014). Holistic face training enhances face processing in developmental prosopagnosia. Brain, 137(Pt 6), 1781-1798.

DeGutis, J., Wilmer, J., Mercado, R. J., \& Cohan, S. (2013). Using regression to measure holistic face processing reveals a strong link with face recognition ability. Cognition, 126(1), 87-100.

Dennett, H. W., McKone, E., Tavashmi, R., Hall, A., Pidcock, M., Edwards, M., \& Duchaine, B. (2011). The Cambridge Car Memory Test: a task matched in format to the Cambridge Face Memory Test, with norms, reliability, sex differences, dissociations from face memory, and expertise effects. Behavior Research Methods, 44(2), 587605.

Duchaine, B., Germine, L., \& Nakayama, K. (2007). Family resemblance: ten family members with prosopagnosia and within-class object agnosia. Cognitive Neuropsychology, 24(4), 419-430.

Duchaine, B., \& Nakayama, K. (2006a). The Cambridge Face Memory Test: results for neurologically intact individuals and an investigation of its validity using inverted face stimuli and prosopagnosic participants. Neuropsychologia, 44, 576-585.

Duchaine, B., \& Nakayama, K. (2006b). Developmental prosopagnosia: a window to contentspecific face processing. Current Opinion in Neurobiology, 16, 166-173. 
Esins, J., Schultz, J., Stemper, C., Kennerknecht, I., \& Bulthoff, I. (2016). Face perception and test reliabilities in congenital prosopagnosia in seven tests. i-Perception, $7(1), 1$ 37.

Farah, M. J., Wilson, K. D., Drain, M., \& Tanaka, J. N. (1998). What is "special" about face perception? Psychological Review, 105(3), 482-498.

Fitousi, D. (2015). Composite faces are not processed holistically: evidence from the Garner and redundant target paradigms. Attention, Perception \& Psychophysics, 77(6), 2037-2060.

Fitousi, D. (2016). Comparing the role of selective and divided attention in the composite face effect: Insights from Attention Operating Characteristic (AOC) plots and crosscontingency correlations. Cognition, 148, 34-46.

Germine, L. T., Duchaine, B., \& Nakayama, K. (2011). Where cognitive development and aging meet: face learning ability peaks after age 30. Cognition, 118(2), 201-210.

Geskin, J., \& Behrmann, M. (2017). Congenital prosopagnosia without object agnosia? A literature review. Cognitive Neuropsychology, 35(1-2), 4-54.

Gray, K. L. H., Biotti, F., \& Cook, R. (2019). Evaluating object recognition ability in developmental prosopagnosia using the Cambridge Car Memory Test. Cognitive Neuropsychology, 36(1-2), 89-96.

Gray, K. L. H., Bird, G., \& Cook, R. (2017). Robust associations between the 20-item prosopagnosia index and the Cambridge Face Memory Test in the general population. Royal Society Open Science, 4(3), 160923.

Gray, K. L. H., Guillemin, Y., Cenac, Z., Gibbons, S., Vestner, T., \& Cook, R. (2020). Are the facial gender and facial age variants of the composite face illusion products of a common mechanism? Psychonomic Bulletin \& Review, 27(1), 62-69.

Hole, G. (1994). Configurational factors in the perception of unfamiliar faces. Perception, 23(1), 65-74. 
Jenkins, R., Dowsett, A. J., \& Burton, A. M. (2018). How many faces do people know? Proceedings of the Royal Society B - Biological Sciences, 285(1888), 20181319.

Kennerknecht, I., Grüter, T., Welling, B., Wentzek, S., Horst, J., Edwards, S., \& Grüter, M. (2006). First report of prevalence of non-syndromic hereditary prosopagnosia (HPA). American Journal of Medical Genetics, 140A(15), 1617-1622.

Kennerknecht, I., Ho, N. Y., \& Wong, V. C. N. (2008). Prevalence of heriditary prosopagonsia (HPA) in Hong Kong Chinese population. American Journal of Medical Genetics, 146A(22), 2863-2870.

Konar, Y., Bennett, P. J., \& Sekuler, A. B. (2010). Holistic processing is not correlated with face-identification accuracy. Psychological Science, 21(1), 38-43.

Le Grand, R., Cooper, P. A., Mondloch, C. J., Lewis, T. L., Sagiv, N., de Gelder, B., \& Maurer, D. (2006). What aspects of face processing are impaired in developmental prosopagnosia? Brain and Cognition, 61(2), 139-158.

Liu, T. T., \& Behrmann, M. (2014). Impaired holistic processing of left-right composite faces in congenital prosopagnosia. Frontiers in Human Neuroscience, 8, 750.

Macmillan, N. A., \& Creelman, C. D. (1991). Detection Theory: A User's Guide. New York, NY: Cambridge University Press.

Marsh, J., Biotti, F., Cook, R., \& Gray, K. L. H. (2019). The discrimination of facial sex in developmental prosopagnosia. Scientific Reports, 9(19079), 1-8.

Maurer, D., Le Grand, R., \& Mondloch, C. J. (2002). The many faces of configural processing. Trends in Cognitive Sciences, 6(6), 255-260.

McConachie, H. R. (1976). Developmental prosopagnosia. A single case report. Cortex, 12(1), 76-82.

McKone, E., Kanwisher, N., \& Duchaine, B. C. (2007). Can generic expertise explain special processing for faces? Trends in Cognitive Sciences, 11(1), 8-15. 
McKone, E., \& Yovel, G. (2009). Why does picture-plane inversion sometimes dissociate the perception of features and spacing in faces, and sometimes not? Toward a new theory of holistic processing. Psychonomic Bulletin \& Review, 16(5), 778-797.

Murphy, J., \& Cook, R. (2017). Revealing the mechanisms of human face perception using dynamic apertures. Cognition, 169, 25-35.

Murphy, J., Gray, K. L. H., \& Cook, R. (2017). The composite face illusion. Psychonomic Bulletin \& Review, 24(2), 245-261.

Murphy, J., Gray, K. L. H., \& Cook, R. (2020). Inverted faces benefit from whole-face processing. Cognition, 194(104105), 1-9.

Palermo, R., Willis, M. L., Rivolta, D., McKone, E., Wilson, C. E., \& Calder, A. J. (2011). Impaired holistic coding of facial expression and facial identity in congenital prosopagnosia. Neuropsychologia, 49(5), 1226-1235.

Pelli, D. G. (1997). The VideoToolbox software for visual psychophysics: transforming numbers into movies. Spatial Vision, 10(4), 437-442.

Peterson, M. F., Zaun, I., Hoke, H., Jiahui, G., Duchaine, B., \& Kanwisher, N. (2019). Eye movements and retinotopic tuning in developmental prosopagnosia. Journal of Vision, 19(7), 1-19.

Piepers, D. W., \& Robbins, R. A. (2013). A review and clarification of the terms "holistic," "configural," and "relational" in the face perception literature. Frontiers in Psychology, 3(559), 1-11.

Rezlescu, C., Susilo, T., Wilmer, J. B., \& Caramazza, A. (2017). The inversion, part-whole, and composite effects reflect distinct perceptual mechanisms with varied relationships to face recognition. Journal of Experimental Psychology: Human Perception and Performance, 43(12), 1961-1973.

Richler, J. J., \& Gauthier, I. (2014). A meta-analysis and review of holistic face processing. Psychological Bulletin, 140(5), 1281-1302. 
Richler, J. J., Wong, Y. K., \& Gauthier, I. (2011). Perceptual expertise as a shift from strategic interference to automatic holistic processing. Current Directions in Psychological Science, 20(2), 129-134.

Rossion, B. (2008). Picture-plane inversion leads to qualitative changes of face perception. Acta Psychologica, 128(2), 274-289.

Rossion, B. (2013). The composite face illusion: A whole window into our understanding of holistic face perception. Visual Cognition, 21(2), 139-253.

Russell, R., Duchaine, B., \& Nakayama, K. (2009). Super-recognizers: People with extraordinary face recognition ability. Psychonomic Bulletin \& Review, 16(2), 252257.

Shah, P., Gaule, A., Gaigg, S. B., Bird, G., \& Cook, R. (2015). Probing short-term face memory in developmental prosopagnosia. Cortex, 64, 115-122.

Shah, P., Gaule, A., Sowden, S., Bird, G., \& Cook, R. (2015). The 20-item prosopagnosia index (PI20): a self-report instrument for identifying developmental prosopagnosia. Royal Society Open Science, 2(6), 140343.

Susilo, T., \& Duchaine, B. (2013). Advances in developmental prosopagnosia research. Current Opinion in Neurobiology, 23, 423-429.

Susilo, T., McKone, E., Dennett, H., Darke, H., Palermo, R., Hall, A., . . Rhodes, G. (2010). Face recognition impairments despite normal holistic processing and face space coding: evidence from a case of developmental prosopagnosia. Cognitive Neuropsychology, 27(8), 636-664.

Tanaka, J. W., \& Farah, M. J. (1993). Parts and wholes in face recognition. Quarterly Journal of Experimental Psychology, 46(2), 225-245.

Towler, J., Fisher, K., \& Eimer, M. (2018). Holistic face perception is impaired in developmental prosopagnosia. Cortex, 108, 112-126.

Tsao, D. Y., \& Livingstone, M. S. (2008). Mechanisms of face perception. Annual Review of Neuroscience, 31, 411-437. 
Ulrich, P. I., Wilkinson, D. T., Ferguson, H. J., Smith, L. J., Bindemann, M., Johnston, R. A., \& SchmalzI, L. (2017). Perceptual and memorial contributions to developmental prosopagnosia. Quarterly Journal of Experimental Psychology, 70(2), 298-315.

Van Belle, G., De Graef, P., Verfaillie, K., Busigny, T., \& Rossion, B. (2010). Whole not hole: Expert face recognition requires holistic perception. Neuropsychologia, 48(9), 26202629.

Van Belle, G., De Graef, P., Verfaillie, K., Rossion, B., \& Lefèvre, P. (2010). Face inversion impairs holistic perception: Evidence from gaze-contingent stimulation. Journal of Vision, 10(5), 1-10.

Verfaillie, K., Huysegems, S., De Graef, P., \& Van Belle, G. (2014). Impaired holistic and analystic face processing in congenital prosopagnosia: Evidence from the eyecontingent mask/window paradigm. Visual Cognition, 22(3), 503-521.

Wenger, M. J., \& Townsend, J. T. (2001). Faces as gestalt stimuli: Process characteristics. In M. J. Wenger \& J. T. Townsend (Eds.), Computational, geometric, and process perspectives on facial cognition (pp. 229-284). Mahwah, New Jersey: Lawrence Erlbaum Associates.

Willenbockel, V., Sadr, J., Fiset, D., Horne, G. O., Gosselin, F., \& Tanaka, J. W. (2010). Controlling low-level image properties: The SHINE toolbox. Behavior Research Methods, 42(3), 671-684.

Young, A. W., Hellawell, D., \& Hay, D. C. (1987). Configurational information in face perception. Perception, 42(11), 1166-1178. 


\section{Figures}

Figure 1

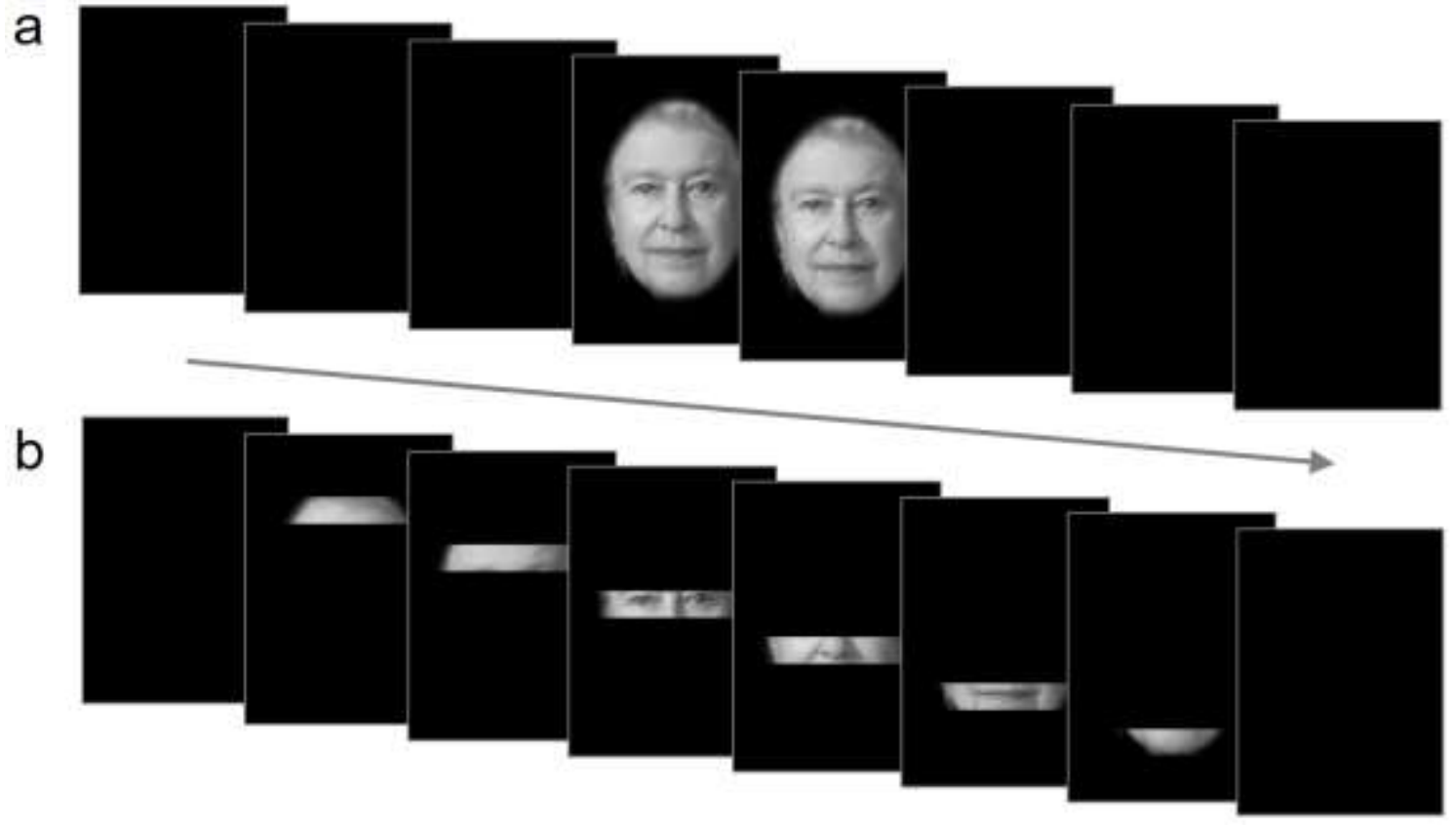

Figure 1: (a) In the whole-face condition target faces were presented in their entirety for 500 ms. (b) In the aperture condition target faces were inspected through a viewing window that moved across the face with a downwards trajectory that lasted 6.2 seconds. 
Figure 2
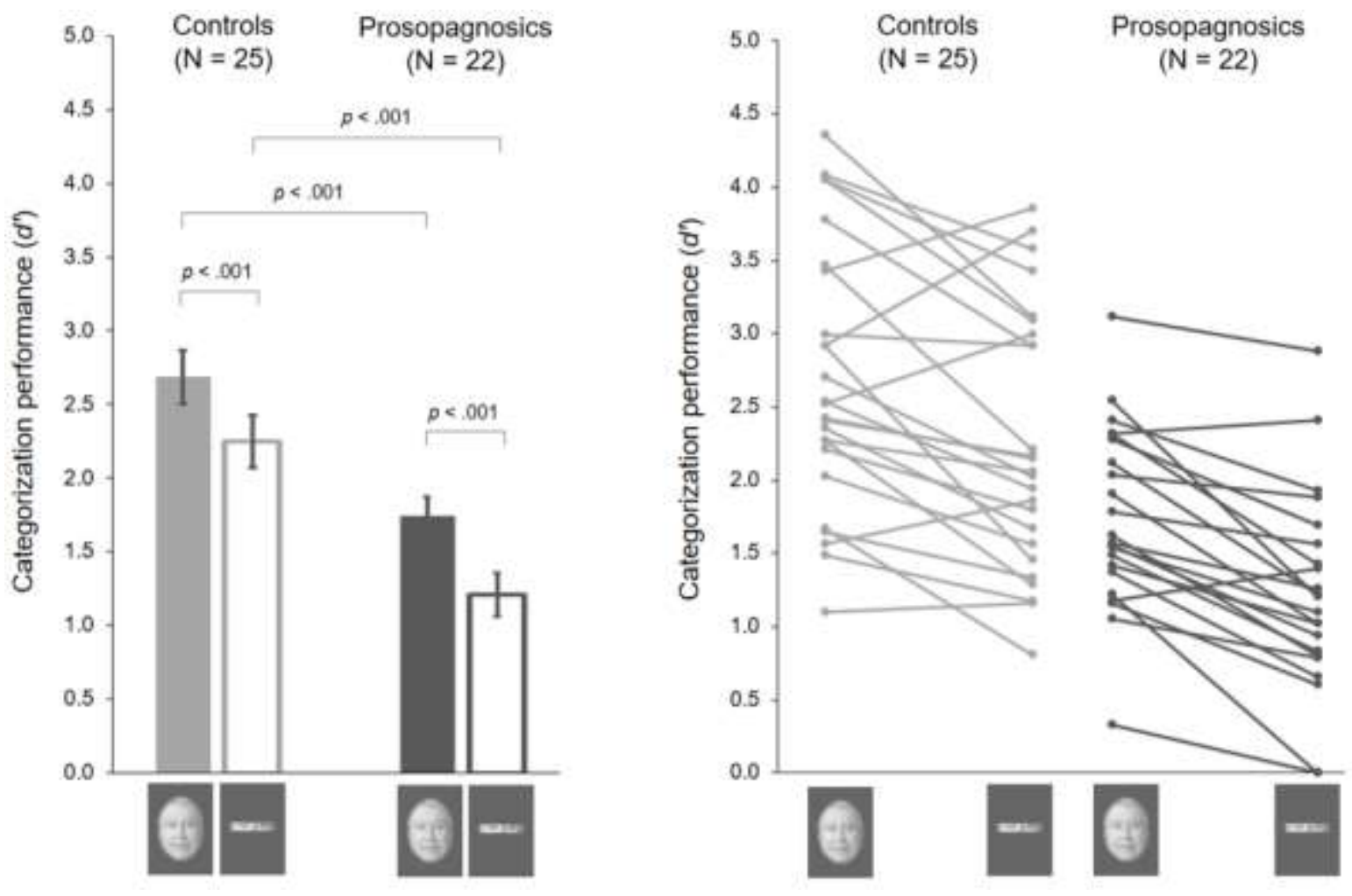

Figure 2: Categorization performance for the prosopagnosics and typical controls. Error bars denote \pm 1 SEM. 
Figure 3

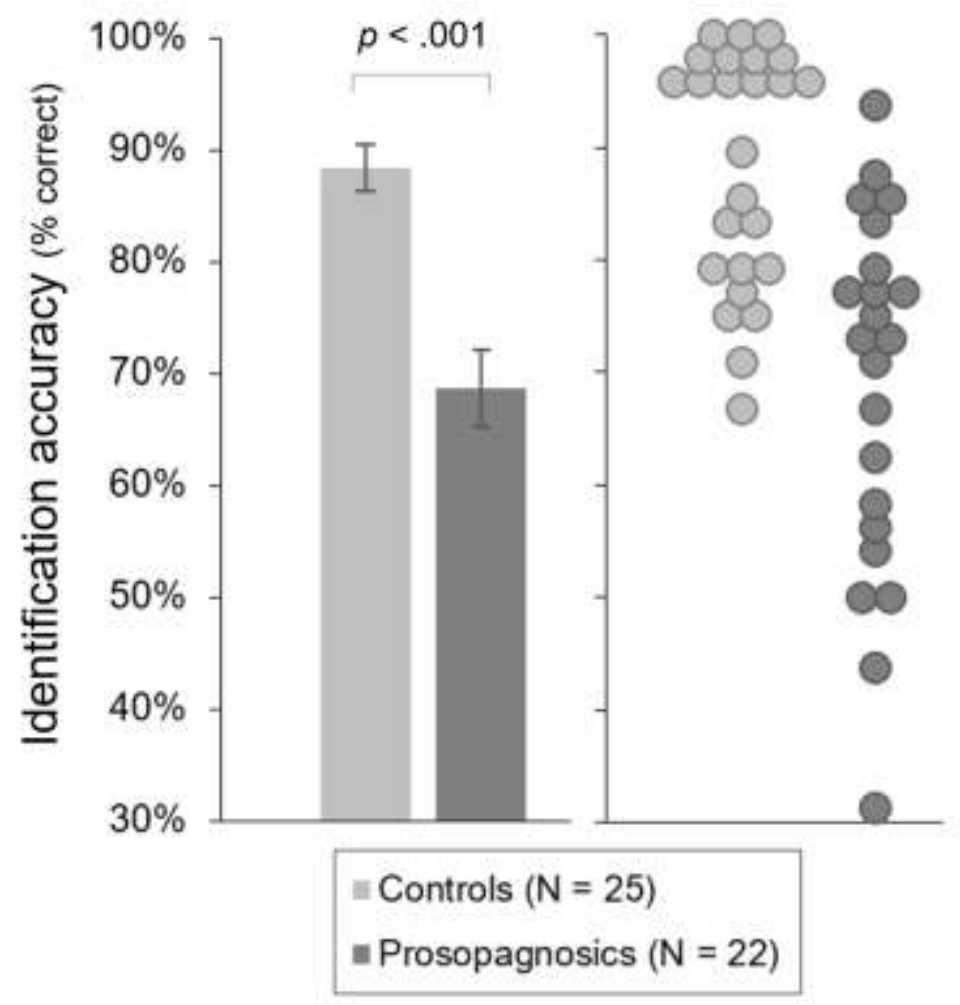

Figure 3: Face recognition performance for the prosopagnosics and typical controls when tested under free-viewing conditions. Error bars denote \pm 1 SEM. 


\section{Tables}

Table 1: Diagnostic information for the DP participants. Scores on the CFPT indicate the number of sorting errors made in the upright condition. ${ }^{*}<1$ SD below typical mean; ${ }^{* *}<$ 2SDs below typical mean; ${ }^{* * *}<3$ SDs below typical mean.

\begin{tabular}{|c|c|c|c|c|c|c|}
\hline & Age & Gender & $\mathrm{Pl} 20$ & CFMT & CFPT & CCMT \\
\hline 1 & 59 & $F$ & $91^{\star \star *}$ & $58.3^{\star *}$ & $60^{* \star *}$ & 66.7 \\
\hline 2 & 44 & $\mathrm{~F}$ & $82^{\star \star \star}$ & $56.9^{\star *}$ & $48^{*}$ & $37.5^{\star \star}$ \\
\hline 3 & 28 & $\mathrm{~F}$ & $72^{\star \star *}$ & $61.1^{\star *}$ & $58^{* * *}$ & $51.4^{*}$ \\
\hline 4 & 54 & $\mathrm{~F}$ & $78^{\star \star \star}$ & $65.3^{\star \star}$ & 32 & $58.3^{*}$ \\
\hline 5 & 44 & $F$ & $82^{\star \star *}$ & $52.8^{\star \star \star}$ & $62^{* \star *}$ & 66.7 \\
\hline 6 & 60 & $\mathrm{~F}$ & $76^{\star \star *}$ & $59.7^{\star \star}$ & $64^{\star \star *}$ & $47.2^{\text {** }}$ \\
\hline 7 & 26 & $\mathrm{~F}$ & $81^{\star \star \star}$ & $65.3^{\star \star}$ & 36 & $47.2^{\star \star}$ \\
\hline 8 & 28 & $\mathrm{~F}$ & $74^{\star \star \star}$ & $58.3^{\star \star}$ & $48^{*}$ & $59.7^{\star}$ \\
\hline 9 & 45 & $\mathrm{~F}$ & $88^{\star \star \star}$ & $56.9^{\star \star \star}$ & $60^{\star \star \star}$ & $59.7^{*}$ \\
\hline 10 & 51 & $M$ & $70^{\star \star \star}$ & $51.4^{\star \star \star}$ & 36 & $52.8^{*}$ \\
\hline 11 & 52 & $M$ & $73^{\star \star \star}$ & $47.2^{\star \star \star}$ & $44^{*}$ & 93.1 \\
\hline 12 & 26 & $M$ & $75^{\star \star \star}$ & $56.9^{* * *}$ & 34 & 76.4 \\
\hline 13 & 29 & $M$ & $77^{\star \star \star}$ & $54.2^{\star \star \star}$ & 50 ** & $41.7^{\star \star}$ \\
\hline 14 & 26 & $\mathrm{~F}$ & $80^{\star \star \star}$ & $48.6^{\star \star \star}$ & $42^{\star}$ & $55.6^{\star}$ \\
\hline 15 & 28 & $\mathrm{~F}$ & $71^{\star \star *}$ & $58.3^{\star \star}$ & 20 & 81.9 \\
\hline 16 & 32 & $F$ & $95^{\star \star \star}$ & $55.6^{\star * *}$ & $62^{* \star \star}$ & 65.3 \\
\hline 17 & 26 & $\mathrm{~F}$ & $89^{\star \star \star}$ & $41.7^{\star \star \star}$ & $54^{\star *}$ & $44.4^{* *}$ \\
\hline 18 & 27 & $F$ & $82^{\star \star *}$ & $62.5^{\star \star}$ & 28 & $51.4^{*}$ \\
\hline 19 & 27 & $\mathrm{~F}$ & $76^{\star \star \star}$ & $52.8^{\star \star \star}$ & 38 & $45.8^{\text {** }}$ \\
\hline 20 & 31 & $\mathrm{~F}$ & $81^{\star \star \star}$ & $61.1^{\star *}$ & $40^{*}$ & $52.8^{*}$ \\
\hline 21 & 37 & $\mathrm{~F}$ & $83^{\star * *}$ & $59.7^{\star \star}$ & 34 & $43.0^{\text {** }}$ \\
\hline \multirow[t]{4}{*}{22} & 32 & $\mathrm{~F}$ & $87^{\star \star \star}$ & $30.6^{\star \star \star}$ & $40^{*}$ & 66.7 \\
\hline & & DP mean: & $\begin{array}{r}80.1 \\
6.8\end{array}$ & $\begin{array}{r}55.2 \\
8.0\end{array}$ & $\begin{array}{l}45.0 \\
12.5\end{array}$ & $\begin{array}{l}56.9 \\
14.4\end{array}$ \\
\hline & \multirow{2}{*}{\multicolumn{2}{|c|}{$\begin{array}{l}\text { Comparison mean: } \\
\text { Comparison SD: }\end{array}$}} & 38.0 & 85.0 & 29.4 & 73.5 \\
\hline & & & 9.1 & 8.9 & 9.4 & 12.6 \\
\hline
\end{tabular}

$\mathrm{Nb}$. Comparison data $(\mathrm{N}=54)$ for the PI20, CFMT, and CFPT were taken from Biotti et al. (2019), Neuropsychologia. Comparison data $(N=61)$ for the CCMT were taken from Gray et al. (2019), Cognitive Neuropsychology. 
Table 2: Correlations (Pearson's $r$ ) between diagnostic test scores and task performance for the DP participants. None of the correlations were significant at $p<.05$.

\begin{tabular}{lccc}
\hline & $\begin{array}{c}\text { Whole Face } \\
(\mathrm{WF})\end{array}$ & $\begin{array}{c}\text { Aperture } \\
(\mathrm{A})\end{array}$ & $\begin{array}{c}\text { Aperture decrement } \\
(\text { WF-A })\end{array}$ \\
\hline PI20 & -.174 & .067 & -.397 \\
\hline CFMT & .068 & .064 & -.006 \\
\hline CFPT & -.310 & -.192 & -.153 \\
\hline CCMT & -.050 & .030 & -.133 \\
\hline
\end{tabular}




\section{Evidence of holistic face processing in developmental prosopagnosia}

\section{Maria Tsantani, Katie L. H. Gray, \& Richard Cook}

\section{Supplementary material}

\section{Main experiment}

Participants' nationality categorization responses were analyzed using signal detection theory. A response of 'British' was classed as a 'hit' if it followed the presentation of a British person's face and as a 'false alarm' if it followed the presentation of an American person's face. The resulting d-prime ( $d$ ) statistics were used to infer participants' ability to recognize, and thereby classify the nationality of the famous faces in the whole-face and aperture presentation conditions. In the main text we report unadjusted estimates of $d^{\prime}$ based on all trials. However, we also derived a second set of adjusted $d^{\prime}$ estimates having removed trials that presented a celebrity which the participant did not know by name. The analysis of these adjusted values is described below.
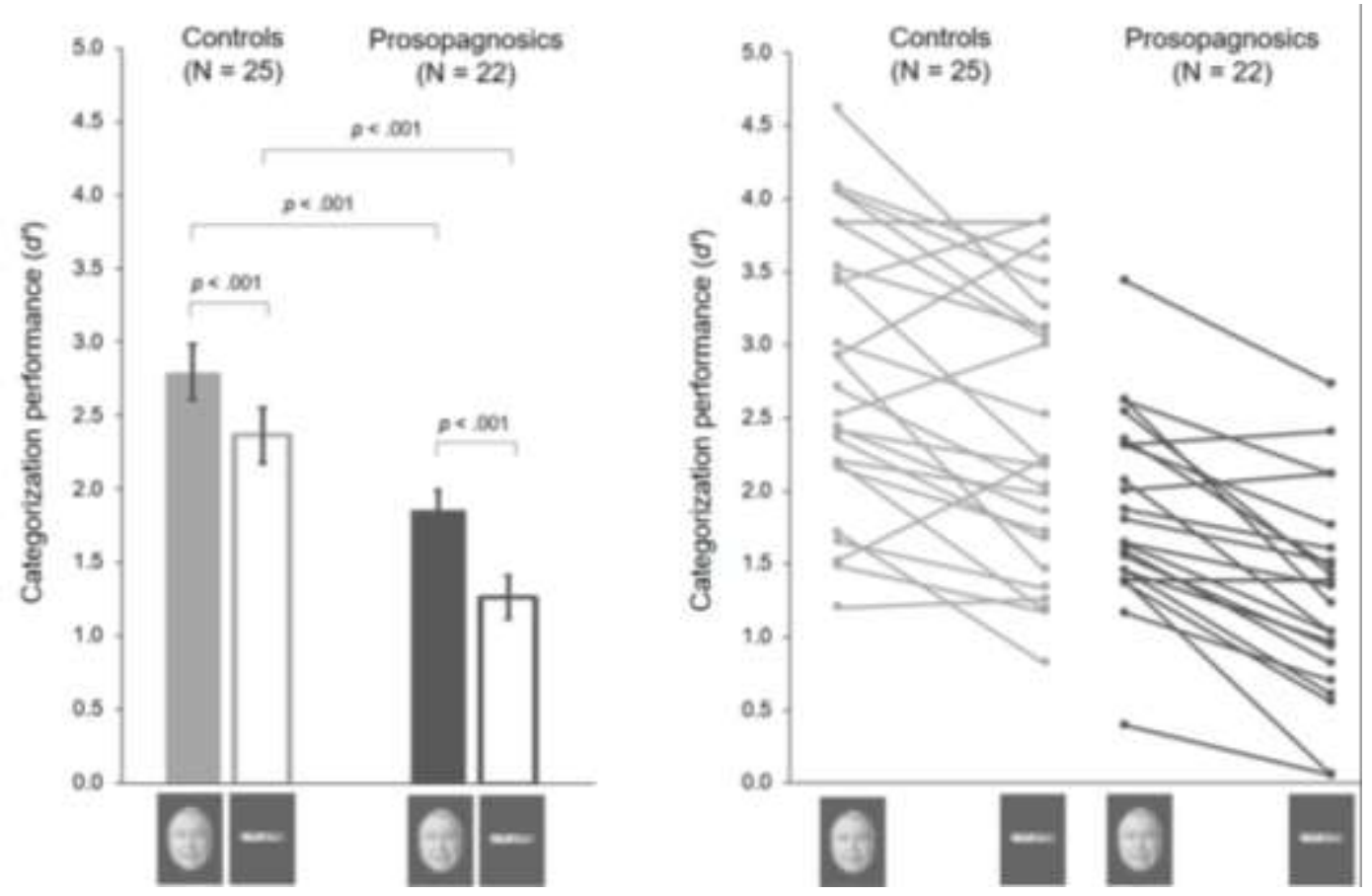

Figure S1: Categorization performance for the prosopagnosics and typical controls. Error bars denote \pm 1 SEM.

The distributions of $d$ 'statistics (Figure S1) were subjected to ANOVA with Viewing Condition (whole-face, aperture) as a within-subjects factor, and Group (DP, control) as a between-subjects factor. The analysis revealed a significant main effect of Viewing Condition 
$\left[F(1,45)=45.709, p<.001, \eta^{2}=.504\right]$, whereby whole-face presentation afforded superior categorization. Both the control (whole-face: $M=2.806, S D=.951$; aperture: $M=2.375, S D$ $=.942)\left[t(24)=3.613, p<.01, d=.441, \mathrm{Cl}_{95 \%}=.173, .703\right]$ and DP (whole-face: $M=1.865$, $S D=.646$; aperture: $M=1.271, S D=.693)\left[t(21)=6.753, p<.001, d=.855, \mathrm{Cl}_{95 \%}=.512\right.$, 1.253] groups showed significant effects of Viewing Condition. The analysis also revealed a significant main effect of Group $\left[F(1,45)=19.748, p<.001 \eta^{2}=.305\right]$, whereby the typical observers out-performed the DPs. Relative to the typical controls, the DPs were impaired in both the whole-face $\left[t(45)=3.912, p<.001, d=1.124, \mathrm{Cl}_{95 \%}=.519,1.758\right]$ and aperture $\left[t(45)=4.525, p<.001, d=1.301, \mathrm{Cl}_{95 \%}=.682,1.951\right]$ viewing conditions. We observed no interaction between Viewing Condition and Group $\left[F(1,45)=1.163, p=.287, \eta^{2}=.025\right]$. We re-ran the foregoing analyses with observer gender as an additional between-subjects factor to determine whether the imbalance had any effect on our results. As expected, none of the main effects or interactions approached significance (all $F s<1.0$, all $p$ 's $>.35$ ).

\section{Famous face recognition under free viewing conditions}

In the main text we report unadjusted rates of identification accuracy (the total number of hits for each individual expressed as a $\%$ of the total number or items). However, we also derived a second adjusted measure: the total number of hits for each individual expressed as a $\%$ of the total number of celebrities who they knew by name. The analysis of these adjusted values is described here.

Once again a clear group difference was evident (DPs: $M=74.1 \%, S D=16.7 \%$; Controls: $M$ $=90.5 \%, S D=9.7 \%)\left[t(45)=4.185, p<.001, d=1.203, \mathrm{Cl}_{95 \%}=.592,1.843\right]$. Significant correlation was seen between the adjusted sensitivity estimates derived for the aperture and whole-face viewing conditions and participants' identification ability under free-viewing conditions, in the combined sample [aperture: $r=.612, p<.001$; whole-face: $r=.696, p<$ .001 ] and in the control [aperture: $r=.582, p<.01$; whole-face: $r=.738, p<.001$ ] group independently. In the DP group, the correlation was significant for whole-faces $[r=.564, p<$ $.01]$, but only approached significance for aperture faces $[r=.406, p=.061]$. There was no effect of observer gender on the number of faces recognized $[t(45)=1.278, p=.208, d=$ $\left..377, \mathrm{Cl}_{95 \%}=-.212, .975\right]$. 
Table S1. Names of the famous people whose faces were presented in the experiments.

\begin{tabular}{cccc}
\hline & British & & American \\
\hline Women & Men & Women & Men \\
\hline Adele & Andy Murray & Angelina Jolie & Ben Stiller \\
Audrey Hepburn & Benedict Cumberbatch & Anne Hathaway & Bill Clinton \\
Emma Watson & Colin Firth & Cameron Diaz & Brad Pitt \\
Helena Bonham-Carter & Daniel Craig & Jennifer Aniston & Elvis Presley \\
Jodie Whittaker & David Cameron & Julia Roberts & George W. Bush \\
Kate Middleton & David Tennant & Madonna & George Clooney \\
Kate Moss & Gordon Ramsey & Marilyn Monroe & Johnny Depp \\
Katie Hopkins & Hugh Grant & Meryl Streep & Leonardo DiCaprio \\
Keira Knightley & Jamie Oliver & Michelle Pfeifer & Mark Zuckerberg \\
Margaret Thatcher & Rowan Atkinson & Natalie Portman & Matt Damon \\
Queen Elizabeth & Simon Cowell & Sandra Bullock & Matt LeBlanc \\
Victoria Beckham & Tony Blair & Scarlett Johansson & Tom Hanks \\
\hline
\end{tabular}

